\title{
Drought changes and the mechanism analysis for the North American Prairie
}

\author{
Ge YU' ${ }^{1 *}$, Dave SAUCHYN², YongFei $\mathrm{LI}^{1}$ \\ ${ }^{1}$ State Key Laboratory of Lake Science and Environment, Nanjing Institute of Geography and Limnology, Chinese Academy of \\ Sciences, Nanjing 210008, China; \\ ${ }^{2}$ Prairie Adaptation and Research Collaborative, University of Regina, Regina S4S 7J7, Canada
}

\begin{abstract}
The worst droughts in the central part of the North American Prairie in the past several hundred years have been reconstructed from tree-ring chronologies, suggesting that some drought years have exceeded the severity shown by the gauge record. A general circulation model of the Geophysical Fluid Dynamics Laboratory (GFDL) has simulated climate changes for the area during the past 250 years driven by climatic forces, providing scenarios of extreme climate that can further diagnose the mechanisms. This study refined the drought signals from the tree ring data and GFDL modeling at inter-annual and decadal time scales and analyzed the potential mechanisms driving the droughts. Results showed that drought years with summer precipitation lower than the $10^{\text {th }}$ percentiles occurred during 1777-1789, 1847-1861 and 1886-1879 AD in the area. Both tree rings and model revealed that the frequency of droughts has been relatively consistent in a similar timing and frequency with climate change. Monte Carlo analysis have detected that the tree ring chronologies have recorded drought years with probabilities of $9.3 \%-12.8 \%$, and the model has simulated the droughts with probabilities $5.7 \%-17.8 \%$. Under $\mathrm{CO}_{2}$ and aerosol forcing, the GFDL modeled the drought recurrences of 13 years and 25 years, which are very synchronous changes with tree rings and consistent with gauge records. The 20-a and 10-a time scale reoccurrences of droughts are very consistent with solar radiation cycles, and similar to the length of cycles in oceanic records, suggesting that terrestrial precipitation modeling is properly driven from sun-land-sea dynamics. Detected severity, variability and return periods of droughts from the present study make potential improvements in drought predictions and constructing scenarios for climate impacts and adaptation strategies.
\end{abstract}

Keywords: drought; tree ring chronology; climate modeling; probability; central Prairie

Citation: Ge YU, Dave SAUCHYN, YongFei LI. 2013. Drought changes and the mechanism analysis for the North American Prairie. Journal of Arid Land, 5(1): 1-14.

Climatic droughts in the central Prairie of North America had serious and damaging effects on human society during the past several hundred years (Larid et al., 1996; Sauchyn et al., 2003). The history of this region has been punctuated by the impacts of droughts, with significant costs in terms of social cohesion in the 1930s and financial relief in the 1980s (Sauchyn et al., 2002), and local people had to migrate during the drought period of the mid $19^{\text {th }}$ century and also there is evidence that illness was related to poor water quality during the dry years (Wolfe et al., 2000; Binnema,
2001). Developing scenarios of prairie droughts is an important task for the regional development. Climate simulations from the 2007 IPCC Fourth Assessment Report (AR4) suggested that increasing aridity in response to global warming could expose a larger area of the northern Great Plains to the impacts of drought (IPCC, 2007). Most of the General Circulation Models (GCMs) have also forecasted precipitation changes for the region, and more frequent and extreme departures from mean conditions, including severe droughts (Kutzbach et al., 1996; Boer et al., 2000; Luo and

*Corresponding author: Ge YU (E-mail: geyu@niglas.ac.cn)

Received 2012-04-05; revised 2012-06-10; accepted 2012-07-11

(C) Xinjiang Institute of Ecology and Geography, Chinese Academy of Sciences, Science Press and Springer-Verlag Berlin Heidelberg 2013 
Wood, 2007). A coupled ocean-atmosphere GCM, developed by Geophysical Fluid Dynamics Laboratory (GFDL), USA (Manabe and Stouffer, 1993; Delworth et al., 2012) has simulated a historical climate under the boundary conditions of the historical equivalent $\mathrm{CO}_{2}$ and aerosols from 1766 to 1990 (Haywood et al., 1997). This modeling has captured historical changes of the summer dryness in mid-cotinent (Schubert et al., 2009; Findell and Delworth, 2010). The model can provide a scenario of prairie droughts and can further diagnose the mechanisms behind climate change (e.g. Frankignoul, 1999; Braconnot et al., 2012).

Climate observation from gauge records is a benchmark to check droughts and the modeling, but gauge records in Canada/USA are mostly limited to the $20^{\text {th }}$ century (Zhang et al., 2000). Proxy precipitation before the gauge observation time can be reconstructed from tree ring records (Fritt and Guiot, 1990; Cook et al., 1997), providing climate information over much longer time spans than gauge records. Precipitation reconstructions based on tree rings have undertaken for southern Alberta (Case and MacDonald, 1995), Manitoba (George and Nielse, 2002) and the southern Saskatchewan (Sauchyn and Beaudoin, 1998; Sauchyn et al., 2002) in the area. These studies have reconstructed climate proxies including annual, July-August and summer precipitations that were used as indicator to study the droughts. However, the precipitation proxies obtained from tree ring records contain more or less uncertainty in sampling and/or linear regression modeling (Touchan et al., 1999; New and Hulme, 2000; Meko et al., 2001). It will be much better to compare tree ring records with other independent evidences, practically the results of mechanism-based GCM simulations which can provide not only long-term climate scenarios but also enable us to analyse the mechanisms behind climate change.

This paper attempted to examine the extreme droughts of the past 250 years on the basis of precipitation proxy reconstructed from tree ring chronology, and to evaluate the droughts from GCM-simulations for the central Prairie in order to better detect the drought severity/variability/return periods, diagnose the mechanisms behind climate change, and to im- prove the scenarios reconstructions for climate impacts and adaptation.

\section{Data and methods}

\subsection{Study area and tree ring chronologies}

The central area of the Prairie is located in a semi-arid climate area that has its base on the Canada-USA border $\left(48-50^{\circ} \mathrm{N}, 108-112^{\circ} \mathrm{W}\right)$ (Fig. 1a) in a great plain land with ca $600-800 \mathrm{~m}$ asl elevations. The annual mean temperature is $4.1^{\circ} \mathrm{C}$, with $15.8^{\circ} \mathrm{C}$ in the summer (June-July-August); and the total annual mean precipitation is $294 \mathrm{~mm}$, with $174 \mathrm{~mm}$ in the summer (Wiken, 1986).

In the regional vegetation covers, lodgepole pine (Pinus contorta) is a dominate species in conifer forests and grows in island-distributed hills and mountains of the prairies (Lotan and Perry, 1977; Critchfield, 1980). The temperature regimes vary greatly from the maximum $27^{\circ} \mathrm{C}$ to the minimum $-57^{\circ} \mathrm{C}$. At low elevations in the interior, the tree grows in areas receiving $250 \mathrm{~mm}$ of mean annual precipitation to the highest amount of $500 \mathrm{~mm}$ (Critchfield, 1980). The growth rate of trees varies sensitively with the changes in precipitation, particularly in the growth period of spring-summer and blooming period of the mid-summer (Sheppard and Noble, 1976).

Tree ring samples in the present study were taken from the lodgepole pine from the Cypress Hills, Saskatchewan-Alberta of Canada (CPH: $49.5^{\circ} \mathrm{N}$, $110.0^{\circ} \mathrm{W}$ ) and Bear Paw Mountains, Montana of USA (BPM: $48.25^{\circ} \mathrm{N}, 109.5^{\circ} \mathrm{W}$ ). We also use a published site, the Sweet Grass Hills, Manitoba of Canada (SGH: $48.83^{\circ} \mathrm{N}, 111.5^{\circ} \mathrm{W}$ ) (Sauchyn and Beaudoin, 1998) and take the mean of three tree ring chronologies as a regional feature for the Prairie region to analyse the past droughts and compared with GCM modeling.

The tree ring chronology was obtained by using standard procedures (Cook and Kairiukstis, 1990) that were used to process the tree cores and disks, and to measure ring width to within $0.001 \mathrm{~mm}$. The $\mathrm{CPH}$ tree ring chronology consisted of 58 series of raw ring widths, and the intercorrelation is 0.48 ; while for BPM 29 series, the intercorrelation is 0.50 . The raw data were detrended with a negative exponential curve. 
This detrending removes low frequency variation, which usually reflects tree age and forest stand dynamics.

Using the program ARSTAN (Grissino-Mayer et al., 1996), several indices (ring width standard index, ring width low-pass filter index, ring width residual index and ring width re-whitened residual index) were calculated. These indices are of different characters and functions. For climate representative, we used the Tree Ring Residual Index (TRI) (Cook and Kairiukstis, 1990) to reconstruct the past droughts and to compare with GCM climate simulations. The record length is 246 years (1754-2000 AD) for the CPH (Fig. 1b), 272 years (1727-1998 AD) for the BPM (Fig. 1c), and 246 years for the regional mean (Fig. 1d).

Observations of climate data were derived from gauge records from meteorological stations in the areas: Medicine Hat $\left(50.02^{\circ} \mathrm{N}, 110.72^{\circ} \mathrm{W}\right)$ representing the nearby area of the Cypress Hills, Havre $\left(48.55^{\circ} \mathrm{N}\right.$, $109.77^{\circ} \mathrm{W}$ ) representing the nearby area of the Bears Paw Mountains, and other 6 meteorological stations in the central Prairie area $\left(48-50^{\circ} \mathrm{N}, 108-112^{\circ} \mathrm{W}\right)$ repre-
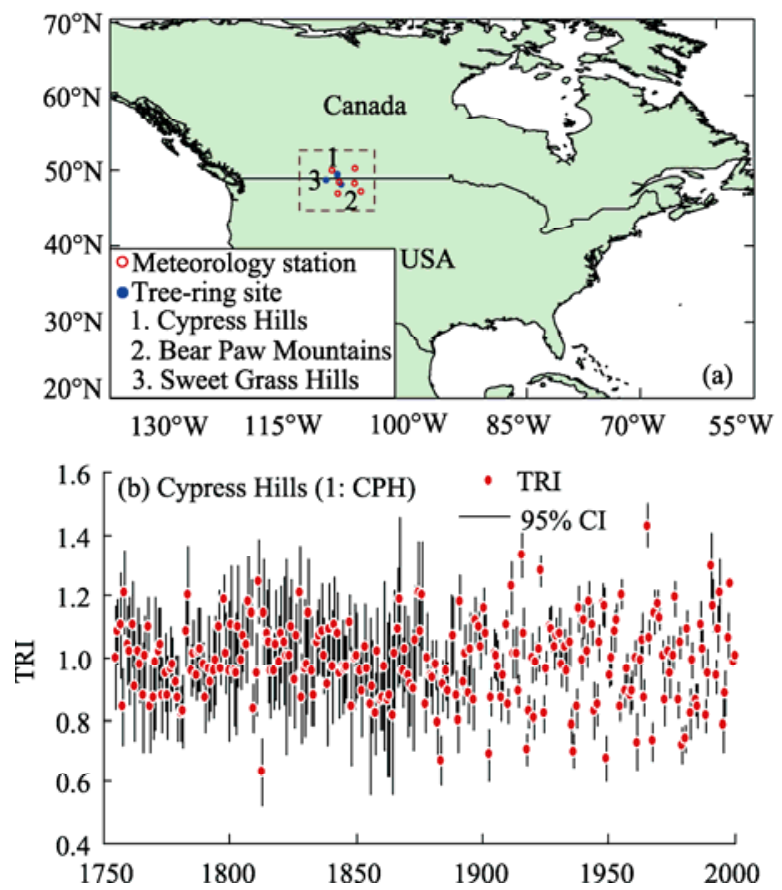

senting the whole region (Fig. 1a). All these data are sourced from Environment Canada (Vincent and Gullett, 1999) and National Climatic Data Center of USA (http://cdo.ncdc.noaa.gov), respectively.

\subsection{GCM climate simulation}

The GFDL is a coupled ocean-atmosphere GCM (Manabe and Stouffer, 1993; Delworth et al., 2012). The model output is rhomboidally truncated at zonal wave number 15, with a spatial resolution of about $7.5^{\circ} \times 4.5^{\circ}$ in horizontal directions, i.e. the output of each monthly array at one level has 48 columns and 40 rows of data points from the southernmost latitude to the north. The climate simulation was forced on basis of the IPCC-IS92a emission scenario (Dixon and Lanzante, 1999). This simulation starts $\mathrm{CO}_{2}$ and aerosol forcing at 1766 levels, runs through the present time (historical equivalent $\mathrm{CO}_{2}$ and aerosols from 1766 to 1990) and out to year 2065. The simulations reveal changes in surface air temperature, hydrology and the thermohaline circulation due to the radiative forcing from anthropogenic greenhouse gases and sulfate aerosols in the GFDL coupled with ocean-atmos-
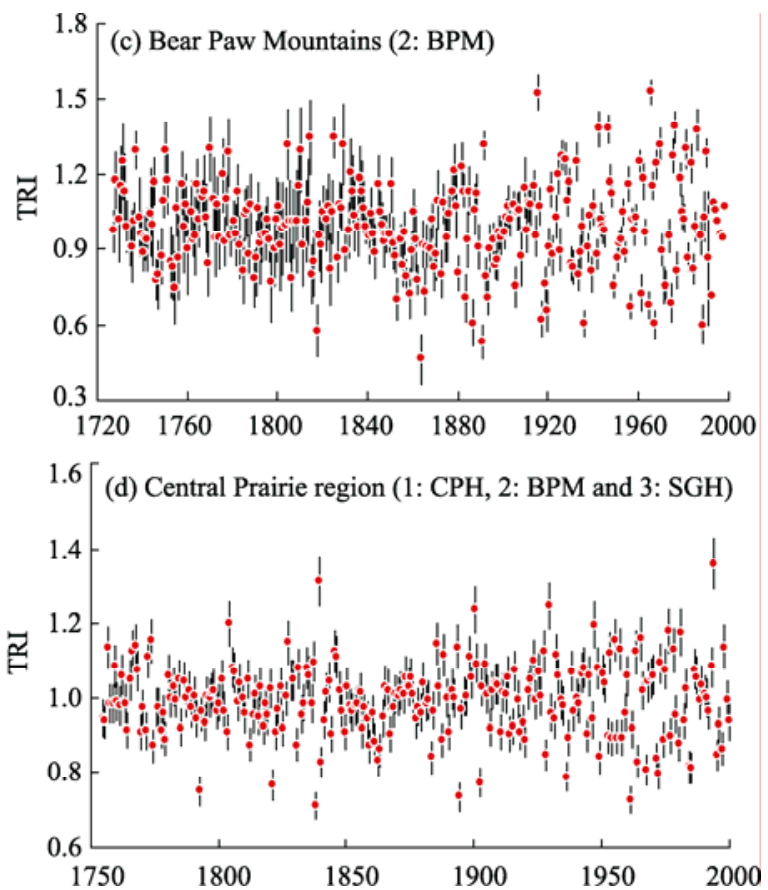

Fig. 1 Locations of tree ring sites and meteorological stations (a) used in the study, and TRI chronologies in Cypress Hills (CPH) (b), Bear Paw Mountains (BPM) (c) and the region (d) 
phere model (Haywood et al., 1997). Output of the $\mathrm{CO}_{2}$ and aerosol experiments was released at the IPCC Data Distribution Center. We downloaded the simulation data from the center and focused our investigation on precipitation changes to determine if they are consistent with the climate records in the region.

Two grid boxes from the GFDL grid web were selected to match the two tree ring sites ( $\mathrm{CPH}$ and $\mathrm{BPM}$ ). Site CPH falls in a grid box at the $32^{\text {nd }}$ row and $34^{\text {th }}$ column with the centroid coordinates of $51.11^{\circ} \mathrm{N}$ and $108.75^{\circ} \mathrm{W}$, and site BPM falls in a grid box at the $31^{\text {st }}$ row and $34^{\text {th }}$ column with the centroid coordinates of $46.66^{\circ} \mathrm{N}$ and $108.75^{\circ} \mathrm{W}$. Additionally, we used 4 grid boxes to match the region of the central Prairie (covering three sites of $\mathrm{CPH}, \mathrm{BPM}$ and SGH). The four grid boxes were selected from the grid web between rows 31-32 and columns 34-35 with the coordinates between $44.3-52.3^{\circ} \mathrm{N}$ and $113-97.5^{\circ} \mathrm{W}$. The geographical locations of the grid boxes and the precipitation simulations were plotted in Fig. 2.

\subsection{Defining drought}

Changes in summer and annual precipitations are closely related to annual moisture conditions in the Prairies, and largely determine drought years in terms of climate and hydrological conditions (Wolfe et al., 2000; Sauchyn et al., 2002). According to records of severe drought years in the $20^{\text {th }}$ century, three periods
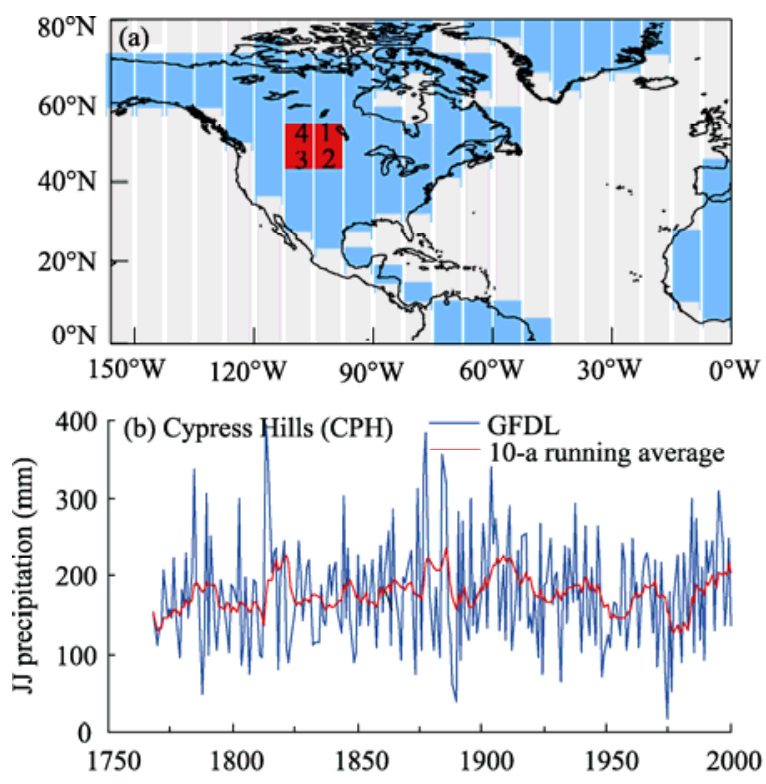

Fig. 2 Locations of grid boxes in the GFDL grid web (a) and the precipitation simulations of June-July (b), June-July-August (d) and annual (c) of the severest droughts happened during 1929-1931, 1959-1961 and 1987-1991. Checking precipitation records, we found a total annual precipitation of 241 $\mathrm{mm}$ with $51.5 \mathrm{~mm}$ in the summer in 1930, an annual $222 \mathrm{~mm}$ with $65.4 \mathrm{~mm}$ in the summer in 1961, and an annual $142 \mathrm{~mm}$ with $67.3 \mathrm{~mm}$ in the summer in 1988 . Precipitations in these drought years are all lower than the $10^{\text {th }}$ percentiles both in annuals and summers. Thus mean precipitations below some low quartiles can indicate drought years. We define that a drought year is a year when annual precipitation is below the lowest $10^{\text {th }}$ percentiles, i.e. a probability in the $10 \%$ quartile:

$$
q=p\left(\mathrm{z}_{\mathrm{i}}<z_{0}\right) .
$$

Where $q$ is the probability of drought year $i$, corresponding to the truncation level $z_{0}$, and $P$ is the notation of cumulative probability.

\subsection{Analysis of probability and return period}

For precipitation reconstructions derived from tree ring chronologies and precipitation simulations from GCM outputs, the full range of extreme values of precipitations may not occur because: (1) sample size is not large enough to catch extreme values; (2) linear regression in tree ring calibration causes reconstructed values to be compressed toward the calibration-period mean (Touchan et al., 1999; Meko et al., 2001); and (3) different sources of uncertainties in GCM control runs
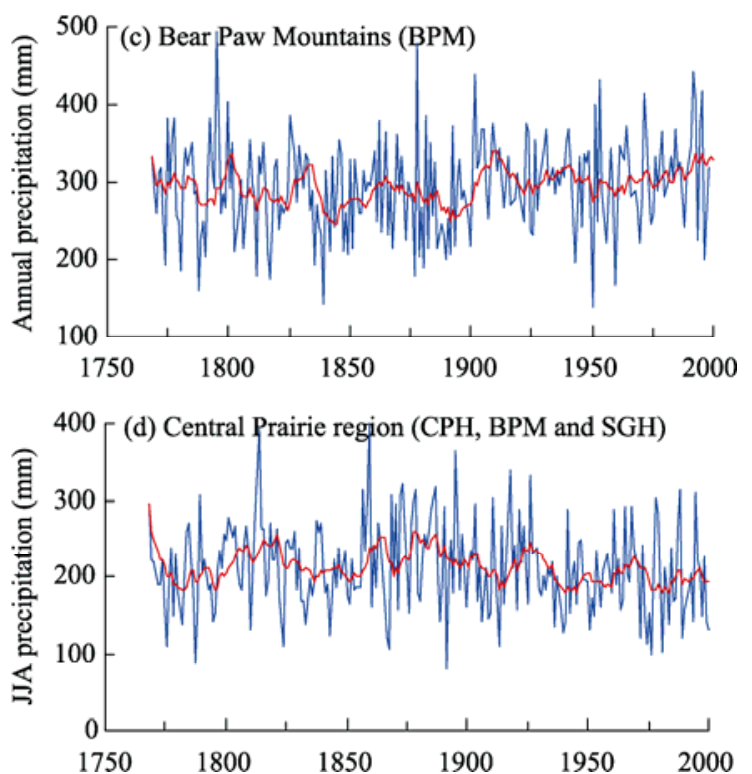
and in GCM ensemble simulations (New and Hulme, 2000; Yu and Shen, 2010) that cause modelings with different behaviors. Thus climate extremes of droughts can be compared in terms of variability and probability (Frankignoul, 1999).

Monte Carlo (MC) analysis approach is useful for obtaining numerical solutions to problems that are too complicated to solve analytically (Hammersley, 1960; Hoffman, 1998). This approach provides probability analysis for estimating the uncertainty of extreme climate, such as in MC random sampling studies to obtain the probabilistic extreme values in error-added tree ring reconstructions, and as in $\mathrm{MC}$ simulating studies to estimate uncertainties from GCM outputs within a probabilistic framework. Here MC probability analysis is used to identify probabilities for tree ring data and GCM data, so comparisons of the probability and return period can be undertaken. The MC model in both tree ring based precipitation and GCM precipitation has a basic formula (Touchan et al., 1999; New and Hulme, 2000):

$$
\hat{u}=\hat{y}+\hat{e} \text {. }
$$

For tree ring series, $\hat{y}$ is the reconstructed precipitation vector, and $\hat{e}$ is error vector that is taken from a standard error of estimate, i.e. the root mean square error of cross-validation (RMSE) in the regression between TRI and gauge precipitation series. For gauge data and GCM outputs, $\hat{y}$ is the precipitation vector and $\hat{e}$ is the error vector that is simply taken from a standard deviation (SD) or RMSE. Both RMSE and $\mathrm{SD}$ are a function of the square root of variance to sample size; hence their orders of magnitude are equal. The climate variables in both modeling and data are June-July precipitation for the $\mathrm{CPH}$, annual precipitation for the BPM, and June-July-August precipitation for the study region.

According to empirical distributions of the data and the goodness fit testing, the prior distribution of $\hat{y}$ follows a normal distribution $\sim \mathrm{N}$ (mean, SD), and $\hat{e}$ follows a uniform distribution $\sim \mathrm{U}$ (max, min), in which the minimum and maximum are taken from SD. Random sampling for the prior probability distribution of $\hat{y}$ and $\hat{e}$ was done for a large sample $(\mathrm{N}=50,000)$ for GFDL, gauge and TRI, respectively. Thus the posterior probability distribution of $\hat{u}$ can be mimicked in an unbiased fashion according to equation 2 .
In addition to the probability analysis, spectral analysis was applied in the present study to estimate periodicities. Spectral analysis can estimate periodicity that is frequency-dependent, and yield information about the underlying physical mechanisms, such as return periods in tree ring chronology (Cook et al., 1997) and in thousand-year control runs in GCM simulations (Collins et al., 2002). Power spectra were calculated by taking the Fourier transform of the autocovariance function of the time series and then applying the Tukey-Hanning window to get a consistent and unbiased estimate (Chatfield, 1975). A lag-window width of 100 years was used to get relatively smooth, bias-free spectra, while retaining the interannual and decadal time scales, in order to examine potential periodicities in GCM simulations and TRI series. A significance test for the periodicity can be done by checking if the estimated spectrum is above the null continuum: a null hypothesis that the estimated spectrum is not different from the underlying spectrum. The spectral peaks above the null continuum suggest significant difference from the underlying spectrum (Bloomfield, 2000). We identify spectral peaks above the null continuum that indicates the frequency greater than $10 \%$ as significant level.

\section{Results}

\subsection{Precipitation predictive model from tree ring records}

Predictive models for the reconstruction of precipitation were derived for each chronology from the linear regression of precipitation data against tree ring width residual index (TRI). Two regression models per chronology were calibrated using different halves of the gauge record (1945-2000) and then validated by using the other half of the record (1890-1945). By trial and error, we tested correlations of the three TRI series with climatic variables of precipitation and temperature for 12 months, 4 seasons and an annual series. Having satisfied by both model results that have to be accepted in the statistic tests, we found that the CPH TRI is significantly correlated with June-July precipitation, the BPM TRI significantly with annual precipitation, and the region significantly with June-July-August precipitation (Table 1). 
Before using the predictive model for reconstruction, we did statistic tests for whole period of 1890-2000. Linear regression between the CPH TRI and June-July precipitation (Fig. 3a) has a relationship of $P=159.20 T R I-54.42$. The correlation coefficient for the whole period is 0.33 ( $F=29.5, P<0.0001)$, reduc-

Table 1 Correlation coefficients between precipitation and TRI chronology from the Cypress Hills (CPH), Bears Paw Mountains (BPM) and the region

\begin{tabular}{|c|c|c|c|c|c|c|}
\hline & \multicolumn{3}{|c|}{ Calibration period (1945-2000) } & \multicolumn{3}{|c|}{ Validation period (1890-1945) } \\
\hline & $\mathrm{CPH}$ & BPM & Region & $\mathrm{CPH}$ & $\mathrm{BPM}$ & Region \\
\hline Annual precipitation & 0.23 & 0.58 & 0.42 & - & 0.59 & 0.29 \\
\hline June-July-August precipitation & 0.44 & 0.29 & 0.43 & - & - & 0.51 \\
\hline June-July precipitation & 0.63 & 0.32 & 0.51 & 0.46 & - & 0.16 \\
\hline Annual temperature & 0.02 & 0.12 & 0.13 & - & - & - \\
\hline June-July-August temperature & -0.12 & -0.15 & -0.12 & - & - & - \\
\hline
\end{tabular}

Note: Boldfaced coefficients are with conference interval 99\%.
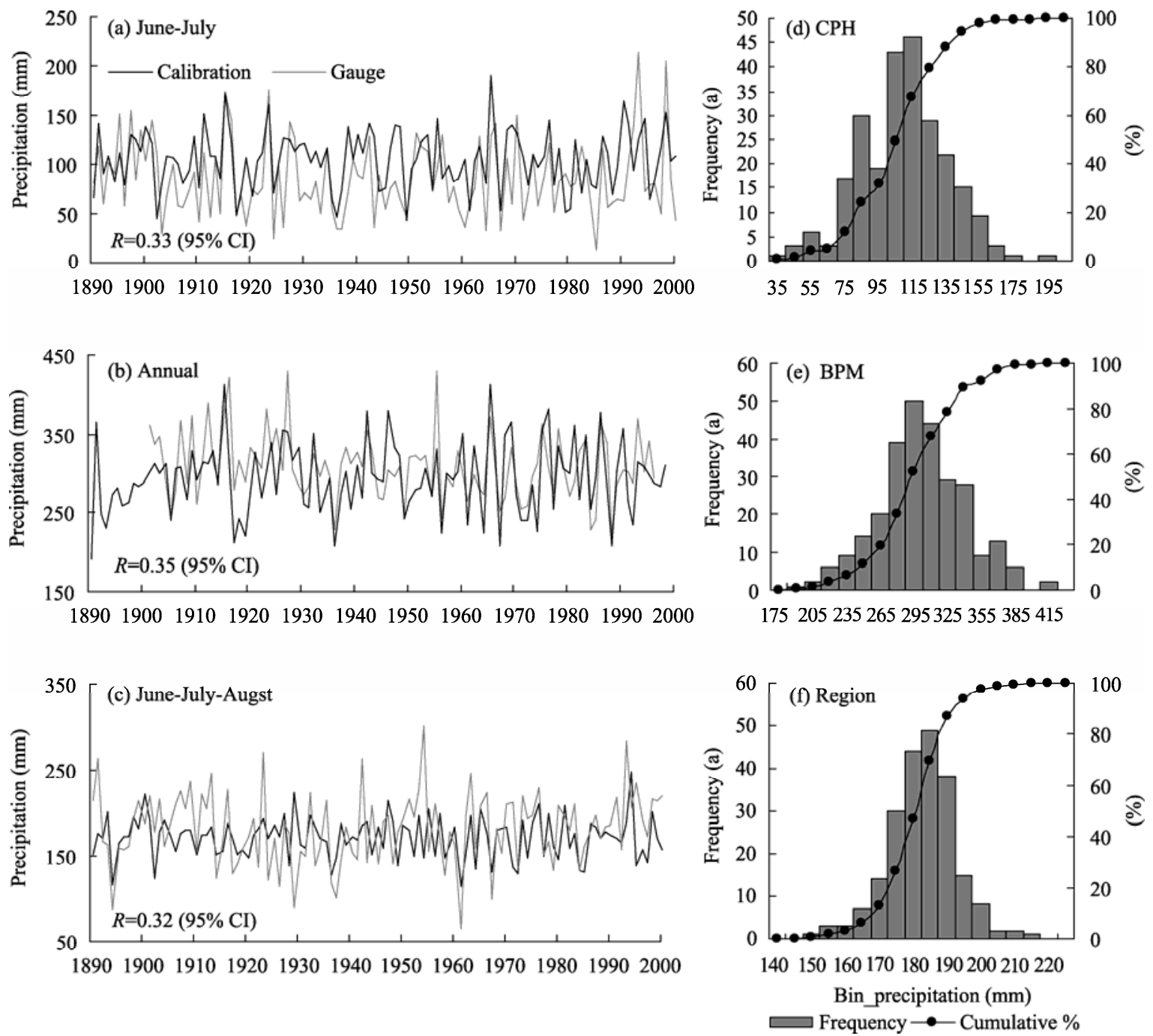

Fig. 3 Precipitation predictive model for June-July precipitation in $\mathrm{CPH}$ (a), annual precipitation in BPM (b), and June-July-August precipitation in the region (c). The right column (d, e and f) is frequency distribution for the three reconstructed series $(a, b$ and $c)$ correspondingly. 
tion error (RE) is 0.28 , and standard error for the calibration period (RMSEc) is 38.99 and for the validation period (RMSEv) is 39.76. The result shows that the RMSEc and RMSEv are of similar magnitudes, and $\mathrm{RE}$ is a positive value. These indices indicate an acceptable result. For site BPM (Fig. 3b), a linear regression between TRI and annual precipitation obtains an equation: $P=218.97 T R I+90.10$. The correlation coefficient for the whole period is 0.35 ( $F=41.0$, $P<0.001$ ), reduction error (RE) is 0.22 , standard error is 64.86 for the calibration period (RMSEc) and 66.04 for the validation period (RMSEv). These results suggest that the predictive model is acceptable.

For probability and periodicity analysis, we further examined the series frequency and the distribution. The CPH TRI reconstruction series generally follows a normal distribution $\sim \mathrm{N}\left(\mathrm{x}, \sigma^{2}\right)$, where mean $\mathrm{x}$ is 104.2 and standard deviation $\sigma$ is 30.02. A Chi-square goodness of fit test to $\sim \mathrm{N}\left(\mathrm{x}, \sigma^{2}\right)$ was performed, and its $\chi^{2}$ value is $62.7(P<0.001)$, suggesting that the series follows a normal distribution at the $99 \%$ confidence level (Figs. 3a and 3d). The BPM TRI precipitation series also follows a normal distribution $\sim \mathrm{N}$ ( $\mathrm{x}$, $\sigma^{2}$ ), where $x=294.2$ and $\sigma=48.13$. The Chi-square goodness of fit test to $\sim \mathrm{N}\left(\mathrm{x}, \sigma^{2}\right)$ gives $\chi^{2}=53.8$, $P<0.001$. The series follows a normal distribution at the $99 \%$ confidence level (Figs. 3b and 3e). The same test was undertaken for the summer precipitation reconstruction in the region (Figs. 3c and 3f), and we obtained an acceptable result that precipitation series follows the normal distribution.

\subsection{Drought strength and frequency}

Statistics of summer/annual precipitation series from gauge, tree ring and GCM were shown in Table 2. The mean and difference between the minimum and maximum give the range of climate changes during the past 250 years. Relative error of the GFDL is ca $10 \%-17 \%$ in the mean and $8 \%-35 \%$ in the max-min difference when compared to the gauge and proxy data. Student test (T-test) showed that means from GFDL annual and summer simulations are equal to those of the TRI-reconstructed precipitations with 95\% conference level.

To examine the drought occurrence and the durations, we used 10-a running average series and selected drought years by a cutoff at the drought criteria
Table 2 Major statistics in precipitation reconstructions

\begin{tabular}{|c|c|c|c|}
\hline & TRI & Gauge & GFDL \\
\hline \multicolumn{4}{|c|}{ Cypress Hills } \\
\hline Variable & \multicolumn{3}{|c|}{ June-July precipitation (mm) } \\
\hline Period (AD) & 1754-2000 & 1884-2000 & 1768-2000 \\
\hline Sample (a) & 247 & 117 & 233 \\
\hline Mean (mm) & 104.16 & 103.13 & 177.77 \\
\hline Median (mm) & 105.29 & 95.0 & 169.41 \\
\hline $\operatorname{Max}(\mathrm{mm})$ & 191.11 & 257.4 & 424.15 \\
\hline Min (mm) & 32.91 & 16.4 & 17.28 \\
\hline $\mathrm{SD}(\mathrm{mm})$ & 30.02 & 47.23 & 73.05 \\
\hline \multicolumn{4}{|c|}{ Bear Paw Mountains. } \\
\hline Variable & \multicolumn{2}{|c|}{ Annual precipitation (mm) } & \\
\hline Period (AD) & 1727-1998 & 1901-1998 & 1768-1998 \\
\hline Sample (a) & 271 & 97 & 233 \\
\hline Mean (mm) & 294.2 & 308.7 & 294.92 \\
\hline Median (mm) & 293.63 & 300.7 & 295.30 \\
\hline Max (mm) & 412.78 & 543.8 & 507.00 \\
\hline $\operatorname{Min}(\mathrm{mm})$ & 176.26 & 142.0 & 138.35 \\
\hline \multirow[t]{2}{*}{$\mathrm{SD}(\mathrm{mm})$} & 48.30 & 83.96 & 60.45 \\
\hline & \multicolumn{2}{|c|}{ Central Prairie } & \\
\hline Variable & June-July-Au & pitation (mm) & \\
\hline Period (AD) & $1767-2000$ & 1882-2000 & 1768-2000 \\
\hline Sample (a) & 234 & 119 & 233 \\
\hline Mean (mm) & 174.48 & 179.78 & 210.61 \\
\hline Median (mm) & 176.70 & 183.84 & 208.84 \\
\hline $\operatorname{Max}(\mathrm{mm})$ & 306.47 & 300.57 & 399.28 \\
\hline $\operatorname{Min}(\mathrm{mm})$ & 72.90 & 65.40 & 80.96 \\
\hline $\mathrm{SD}(\mathrm{mm})$ & 35.62 & 42.99 & 56.82 \\
\hline
\end{tabular}

of precipitation $<10^{\text {th }}$ percentiles (Fig. 4). In the $\mathrm{CPH}$ TRI reconstruction, we observed four drought periods focused on 1772, 1855, 1877-1881 and 1979 (Fig. 4a). Comparably, drought years focused on 1790, 1886 and 1969-1973 in GFDL simulations are generally consistent with the TRI-reconstructed drought years (Fig. 4b). There are four drought periods in the BPM TRI reconstruction. The drought years are focused on 1815, 1857-1961, 1889 and 1930 (Fig. 4c), while drought years focused on 1807, 1820 and 1853-1859 in the GFDL simulations can be compared (Fig. 4d). Four drought periods in the region occurred in 1785, 1812-1817, 1855-1859 and 1958 (Fig. 4e), while drought years around 1847-1850 in the GFDL simulation (Fig. 4f) is in agreement with the TRI in the mid $19^{\text {th }}$ century. Generally speaking, three drought peri- 

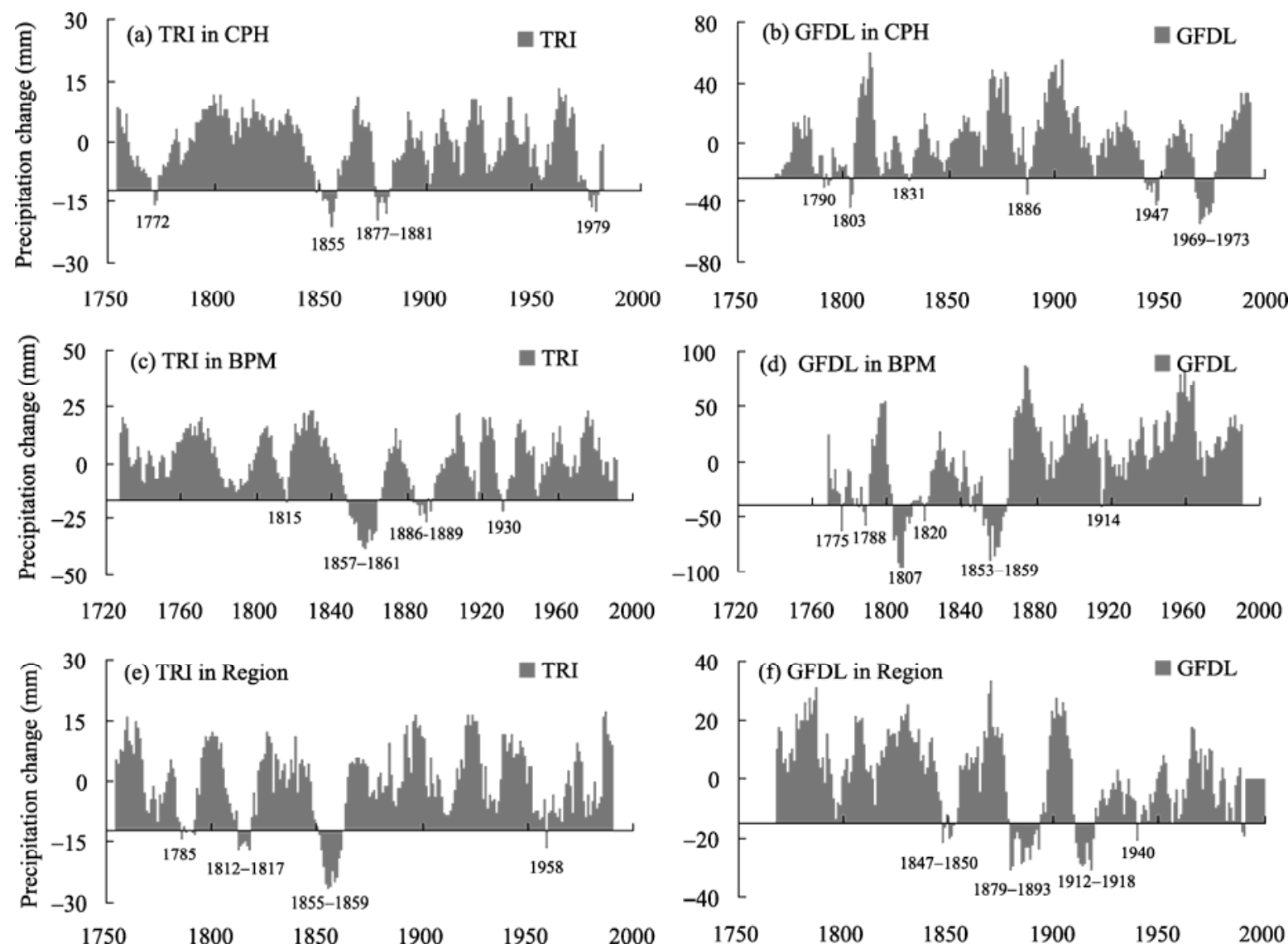

Fig. 4 Drought changes in 10-a running average precipitation series from TRI reconstructions (left) and GFDL simulations (right) in CPH (b), BPM (d) and the region (f). Drought criteria ( $\mathrm{mm}$ ) by using the $10^{\text {th }}$ percentile precipitation was plotted in the horizontal line, and precipitations below the line represent drought years.

ods during 1777-1789, 1847-1861 and 1886-1879 have been captured both by tree ring records and GCM modeling, suggesting that the modeling and tree ring records provide a similar timing and frequency of drought occurrence.

Frequency analysis from GFDL series and TRI series showed similar distributions in CPH (Figs. 5b, 5e and 5 f). The $59 \%-61 \%$ frequency spans 80 percentiles within summer precipitation time series of the gauge, tree ring and modeling. For the small quartiles representing the drought, there is $0.8 \%-0.9 \%$ with the $1^{\text {st }}$ percentile and $8.5 \%-9.0 \%$ with the $10^{\text {th }}$ percentiles in the gauge, TRI and GFDL. Small differences of BPM annual precipitation between the modeling and data also appear at the two tails of the frequency distributions (Figs. 5a, 5d and 5g). The frequencies in GFDL modelling $\left(0.9 \%\right.$ with the $1^{\text {st }}$ percentile and $8.9 \%-$
9.9\% with the $10^{\text {th }}$ percentiles) are generally in agreement with the tree ring data $(0.7 \%-0.9 \%$ and $8.2 \%-9.2 \%$, respectively).

\subsection{Drought probability and return period}

Figure 6 plotted the results of the simulated climate probability using the MC approach for TRI and GFDL: the left column is precipitation probability comparisons, and the middle and right columns are drought probability comparisons. We can see that MC probabilities of GFDL simulations are very similar to distributions of TRI-based June-July and June-July-August precipitations (Figs. 6a and 6c).

We firstly checked MC probabilities at the $10^{\text {th }}$ percentile criteria (Figs. 6a1, 6b1 and 6c1). The GFDL simulated drought with $5.68 \%$ probability at site $\mathrm{CPH}$ (Fig. 6a1), suggesting an underestimation of the low precipitation portion. The model simulated drought 

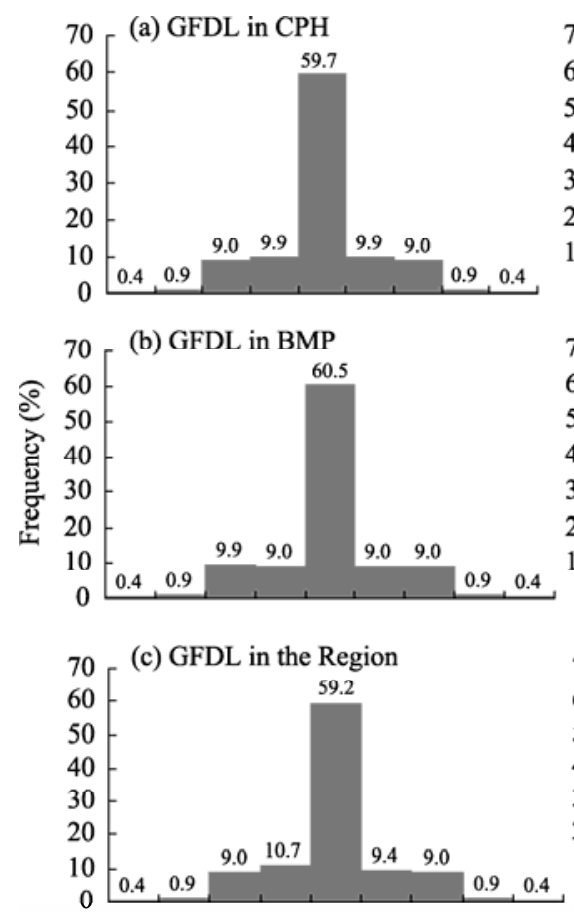

Min $1^{\text {th }} 10^{\text {th }} 20^{\text {th }} 80^{\text {th }} 90^{\text {th }} 99^{\text {th }}>99^{\text {th }}$ Max Precipitation quartile (d) TRI in CPH

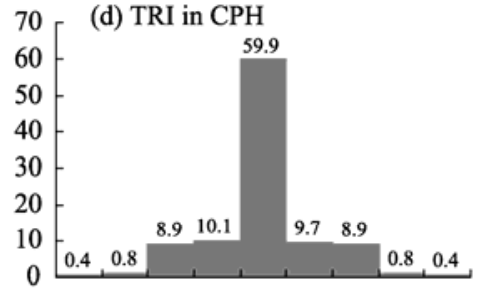

(e) TRI in BMP
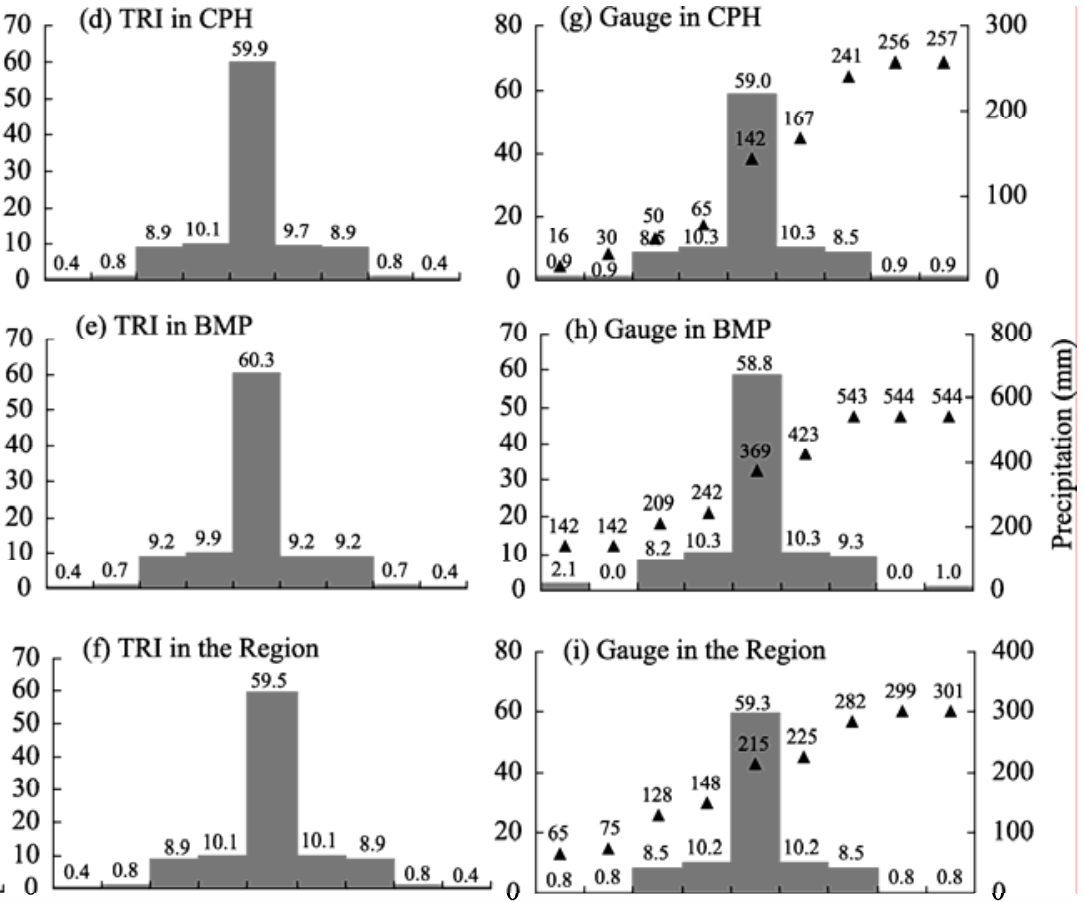

Min $1^{\text {th }} 10^{\text {th }} 20^{\text {th }} 80^{\text {th }} 90^{\text {th }} 99^{\text {th }}>99^{\text {th }}$ Max $\operatorname{Min} 1^{\text {th }} 10^{\text {th }} 20^{\text {th }} 80^{\text {th }} 90^{\text {th }} 99^{\text {th }}>99^{\text {th }} M a x$ Precipitation quartile

Fig. 5 Frequency distribution of GFDL (left column), TRI-reconstruction (middle column) and gauge (right column) for June-July precipitation in $\mathrm{CPH}$, annual precipitation in BPM and June-July-August precipitation in the region

with $17.7 \%$ probability at site BPM (Fig. 6b1), suggesting an overestimate of drought. The modelling captured major portions of drought at $5.7 \%-17.8 \%$ probabilities, within $\pm(5 \%-8 \%)$ errors when compared to the drought criteria of the $10^{\text {th }}$ percentiles of precipitation. However, the probability of GFDL precipitations is $10.4 \%$ in the region (Fig. 6c1), which is very close to the TRI-based probability of $10.0 \%$.

We also checked MC probabilities at the $1^{\text {st }}$ percentile criteria (Figs. 6a2, $6 \mathrm{~b} 2$ and 6c2). Comparably, the MC probabilities are 2.80\% (CPH), 2.30\% (BPM) and $1.99 \%$ (region) in TRI-based precipitation series and $0.89 \%, 2.81 \%$ and $1.42 \%$ in GFDL-modelled precipitation, respectively. Drought probability of the GDFL modelling is in general consistence with tree ring records, within $0.4 \%-3.8 \%$ errors.

Study on the power spectra in the yearly precipitation series has detected the cycle periods. As the highest peaks in each spectrum indicate the major frequencies and periods of the sequence variations, we plotted the spectral frequency through a Low-pass
Gaussian Filter with period $>10$ a for $50 \%$ frequency response. A period of time scales of around (13 \pm 2$)$ a in GFDL modeling is found to be consistent with the TRI and gauge records (Fig. 7). GDFL modeling shows that the period of 21-23 a in summer precipitation series is consistent with the same time scale of gauge records. We further examined drought periods in the 10-a running average series. Two synchronous return periods of time scales of 13-15 a and 23-27 a occurred in GFDL model, which is in agreement with the TRI and gauge data.

\section{Discussion and conclusions}

\subsection{Drought changes during the past 250 years}

In the central Prairie region, lodgepole pine trees grow under an annual precipitation of $250-500 \mathrm{~mm}$ and the tree growth is sensitive to precipitation changes in summer season (Sheppard and Noble, 1976). Our study found that, the pine tree ring-based reconstruction of precipitation is a good indicator of drought 

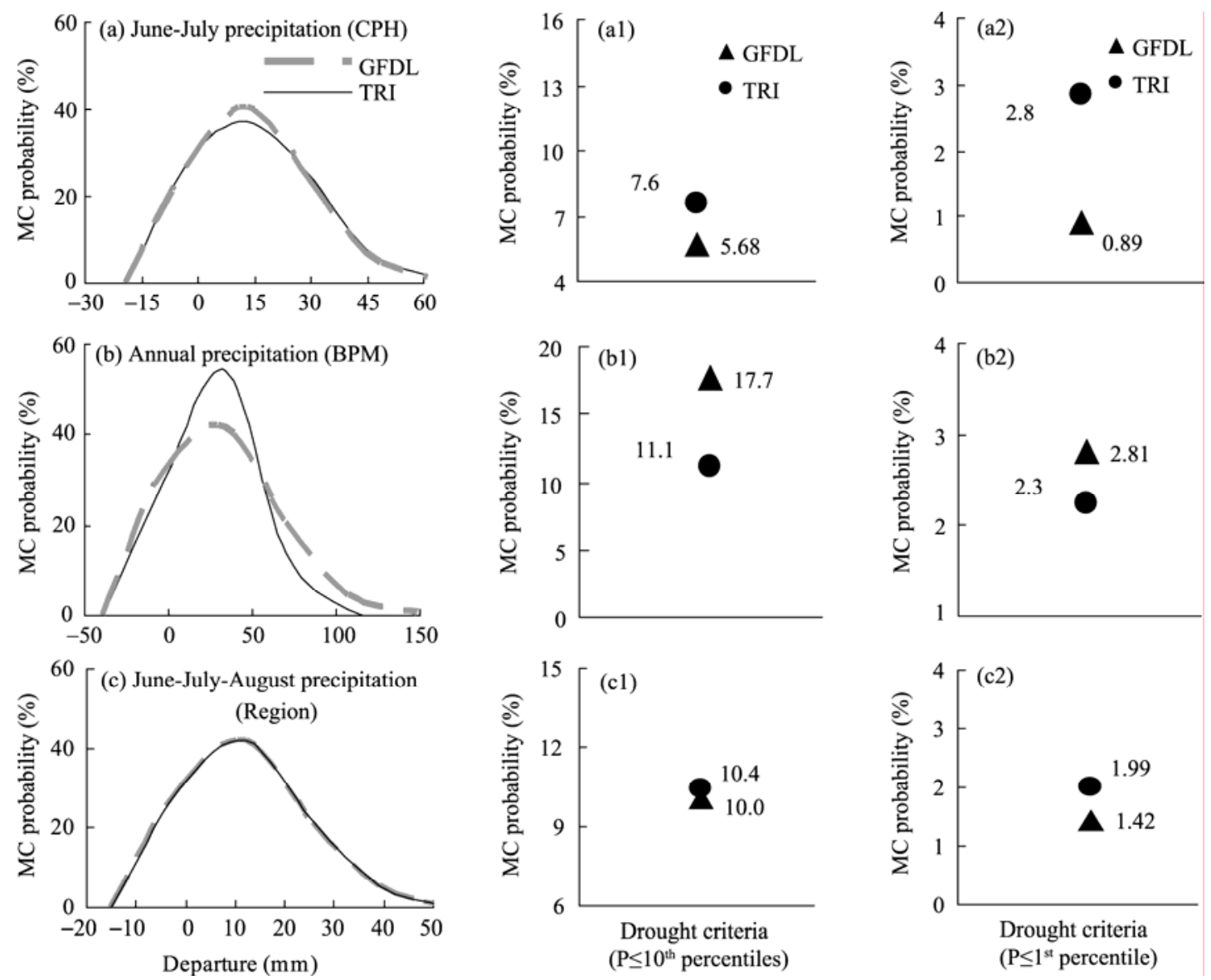

Fig. 6 Comparisons of Monte Carlo probability with GFDL and TRI reconstruction for June-July precipitation in CPH (a), annual precipitation in BPM (b) and June-July-August precipitation in the region (c). Frequency distributions were plotted in left column, MC probabilities at drought criteria $\left(P \leq 10^{\text {th }}\right.$ percentiles) in middle column and at drought criteria $\left(P \leq 1^{\text {st }}\right.$ percentile $)$ in right column.

years in long-term historical time when the precipitation was lower than the $10^{\text {th }}$ percentiles (below 128 $\mathrm{mm}$ of summer precipitation and below $209 \mathrm{~mm}$ of annual precipitation). It has statistically provided the robust relationships between the changes of annual tree ring width of the pine trees and the changes of summer and annual precipitation.

More serious droughts in the Prairie region have been identified from tree ring chronologies than from the shorter gauge records. TRI records of 10-a running average series show the drought periods focused on 1772, 1855 and 1877, respectively, which are 1.7\%$5.5 \%$ higher probability than the gauge criteria in site CPH. Drought periods focused on 1815, 1857 and 1889, respectively, which have $1.1 \%-8.7 \%$ higher probability than the gauge criteria in site BPM. In the present study, a $50 \%$ chance in the dry-half of the distribution is equivalent to a $100 \%$ chance in two tails of the probability distributions, hence a probability greater than $50 \%$ means that the drought event must have occurred, or in other words, the reconstructed annual precipitation is definitely below the gauge record. However, frequencies of the lowest reconstructed precipitation, and the class lower than the $10^{\text {th }}$ percentiles in the gauge records, are less than the gauge threshold. This is because the linear regression between tree ring series and climate data causes reconstructed values to be compressed towards the mean of the calibration period. Thus the linear regression reconstruction represents well the mean value but is insufficient in representing the variability and drought extremes.

We used MC probability analysis to solve this problem. The MC analysis, designed to account for uncertainty in the precipitation reconstruction, indicates that the extreme precipitation can be detected 

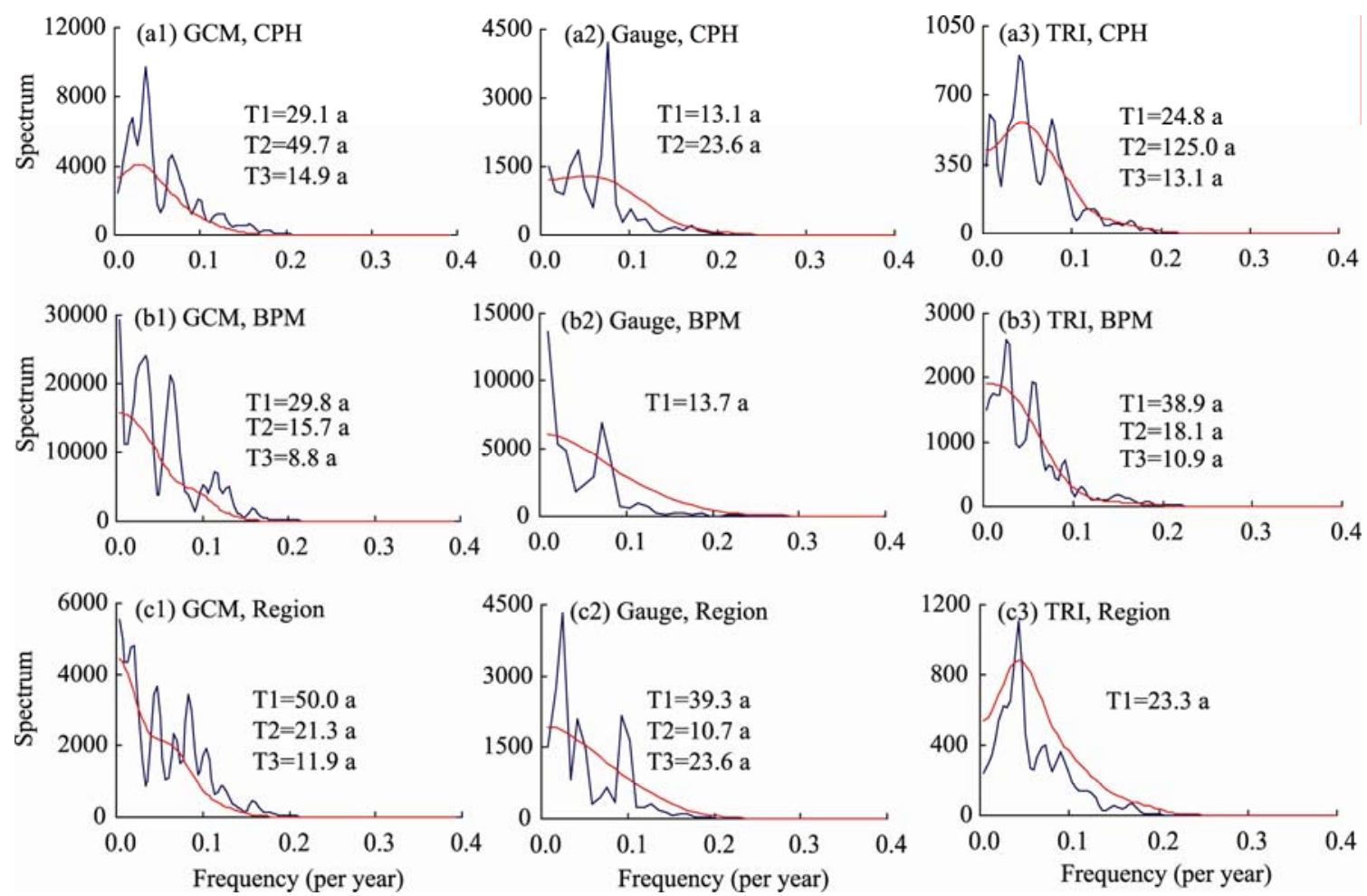

Fig. 7 Power spectrum and return periods for June-July precipitations in CPH (a1-a3), annual precipitations in BPM (b1-b3) and June-July-August precipitations of the region (c1-c3), respectively from GCM (left), gauge (middle) and TRI (left). T1, T2 and T3 represent three return periods calculated by the $1^{\text {st }}, 2^{\text {nd }}$ and $3^{\text {rd }}$ highest frequencies, respectively. Spectrum above the null continuum (red line) represents significant period and the frequency greater than $10 \%$.

using the cross-validation error (RMSE) in the reconstruction series. Consequently the probability of drought events longer than the 10-a running average experienced in the past 250 years can be determined. In the $10^{\text {th }}$ percentiles of drought criteria, we modeled the tree ring chronologies-based drought years with the MC probabilities of $7.6 \%-11.1 \%$, and modeled the GFDL-simulated drought years with the MC probabilities of $5.7 \%-17.7 \%$. For the extreme drought by criteria of the $1^{\text {st }}$ percentile, we modeled the TRI-based drought years with probabilities of $2.0 \%-2.8 \%$, and the GFDL modeled drought years with probabilities of $0.9 \%-2.8 \%$. Thus the probabilities of the lowest $10^{\text {th }}$ percentiles from both TRI and GFDL are very close to the gauge records, and the minimum reconstructed precipitation is similar to the gauge record. The MC probability is higher than the gauge record, and gives drought periods not recorded by the gauge record. Thus the error-added reconstruction provides a convincing basis in probability terms to validate the climate modeling in long ranges and extremes.

\subsection{Mechanism analysis of the droughts}

With the reconstruction of precipitations from tree ring chronology and GCM simulations, we can analyze the causes of the droughts by (1) validating modeling using data, and (2) understanding the known dynamical forces in the modeling (Braconnot et al., 2012). The results of the present study can provide a good understanding for the causes since the GDFL 250-a climate modeling has many agreements with the data, in the time series variability and the drought probability/periodicity.

Spectrum analysis of GCM precipitation simulations shows that for 10-a time scale the frequencies agree with the TRI and gauge records. In terms of internal interactions of the climate system, the decadal periods are also observed in oceanic cycle phenomenon, like the El Niño Southern Oscillation (ENSO), the Pacific Decadal Oscillation (PDO) (Mantua et al., 1997; Bond and Harrison, 2000) and the North Atlantic Oscillation (NAO) (Hurrell, 1995, 2003). The $20^{\text {th }}$ 
century PDO fluctuations were most evident at periodicities of 15 a, 20-30 a and 50-70 a (Minobe, 1997, 1999), and the PDO variability strongly influences summer rainfall and drought in the United States (Nigam et al., 1999). Analyzing the Prairie droughts for the 2000/2001 agricultural year has confirmed dynamical linkages between drought and the North Pacific SST variability (Liu et al., 2004). We think the drought periods simulated by the ocean-coupled atmospheric circulation model responded well to the variability of oceanic circulation and sea surface temperature.

GFDL historical climate modeling was based upon the IPCC-Is92a emission scenario that applies $\mathrm{CO}_{2}$ and aerosol forcing from 1766 to 1990. This simulation, mainly driven by historical changes in the greenhouse-gas emissions, is in better agreement with observed temperature changes when increased atmospheric concentrations of both greenhouse gases and sulfate aerosols are included than with greenhouse gases forcing alone. The present study found that the modeling can detect the major recurrence of cycles of $11-13$ a and $21-25$ a from the two-century proxy precipitation sequence, suggesting that the model spinup driven by the changes in greenhouse-gas emission has validity. The 11-a and 22-a periodic features are reported in sunspot and solar radiation cyclic phenomenon (Hoyt and Schatten, 1997). A number of scientists have used records of ${ }^{14} \mathrm{C}$ in tree rings to investigate the relationships between potential solar forcing mechanisms and climate change where changes in the output of the Sun energetic particles are believed to modulate the production of ${ }^{14} \mathrm{C}$ in the upper atmospheres (Stuiver et al., 1998). It is possible that the approximate sunspot 11- and 22-a cycles identified in the present study are caused by some ocean-linked internal oscillations because the modeling is driven by changes in atmospheric components rather than external solar forcing. This is supported by the GFDL global warming experiments (Dixon and Lanzante, 1999; Dixon et al., 2003), in which the greenhouse-gas induced changes in surface freshwater fluxes are dominant in the North Atlantic thermohaline circulation weakening. Analyses of the GFDL model's ocean oscillation and related surface fluxes (Delworth and Knutson, 2000; Delworth et al., 2012) have revealed that greenhouse-gas induced weakening of the thermohaline circulation could be delayed by several decades in response to the Arctic/North Atlantic oscillation that has been observed from the 1960s to the 1990s (Dixon et al., 2003).

Although it is believed that changes in the mid-continental summer dryness were simulated in the modeling driven by changes in $\mathrm{CO}_{2}$ and aerosol (Haywood et al., 1997), the present work found that GFDL modeling is insufficient in estimating the extreme drought in the Prairie. This implies that other forcing, in addition to the greenhouse-gas emissions, particularly solar variations during the last 250 years as simulation is improved in a sensitivity experiment for the historical climate, affect precipitation change (Collins et al., 2002). To consider external forcing, Earth land surface dynamics would improve the climate simulations. Reconstruction for temperature through the last hundred years (Mann et al., 1999; Dixon et al., 2003) showed a broad-scale decreasing trend before the mid $19^{\text {th }}$ century and an increasing trend after that period in response to changes in greenhouse-gas emissions (Crowley, 2000). Precipitation response to the change in the atmospheric composition is not as direct as temperature. The fact that drought response to changes in atmospheric composition is not linearly additive has cautioned us to pay more attention to the range of precipitation variability, and to determinate the adaptating and decision making on climate change.

As a massive arid land with an area of $1.30 \times 10^{6}$ $\mathrm{km}^{2}$, the North American Prairie is not only sensitive to climate change, but also plays an important role in the feedback of the climate system. The GFDL modeling has suggested that the feedback from land surface in the climate system would amplify and modify external forcing, leading to obvious climate changes in North America (Kutzbach et al., 1996; Schubert et al., 2009; Koster et al., 2010). Increasing aridity in response to global warming could expose a larger area of the Prairie Interior to the impact of droughts.

\section{Acknowledgements}

Financial support for this work was provided by Global Change Research Program of the Ministry of Science and Technology 
of China (2012CB956103), International Partnership Program and External Cooperation Program of the Chinese Academy of Sciences (KZZD-EW-TZ-08, GJHZ1214) and Key Directional Program of the Chinese Academy of Sciences (KZCX2-YW338-2). Many thanks to IPCC Data Distribution Center for data archives, and Dr. Elaine BARROW and Mr. Antoine BERIAULT for assistances during the data analysis.

\section{References}

Binnema T. 2001. Common and Contested Ground: A Human and Environmental History of the Northwestern Plains. Norman: University of Oklahoma Press.

Bloomfield P. 2000. Fourier Analysis of Time Series ( $\left.2^{\text {nd }} e d.\right)$. London: John Wiley \& Sons.

Boer G J, Flato G, Ramsden D. 2000. A transient climate change simulation with greenhouse gas and aerosol forcing: projected climate for the $21^{\text {st }}$ century. Climate Dynamics: 16 : 427-450.

Bond N A, Harrison D E. 2000. The Pacific Decadal Oscillation, air-sea interaction and central north Pacific winter atmospheric regimes. Geophysical Research Letter, 27: 731-734.

Braconnot P, Harrison S P, Kageyama M, et al. 2012. Evaluation of climate models using palaeoclimatic data. Nature Climate Change, 2: 417-424.

Case R A, MacDonald G M. 1995. Dendroclimatic reconstruction of annual precipitation on the western Canada Prairies since A.D. 1505 from Pinus flexilis James. Quaternary Research, 44: 267-275.

Chatfield C. 1975. The Analysis of Time Series: Theory and Practice. London: Chapman and Hall.

Collins M, Osborn T J, Tett S F B, et al. 2002. A comparison of variability of a climate model with paleotemperature estimates from a network of tree ring density. Journal of Climate, 15: 1497-1515.

Cook E R, Kairiukstis L A. 1990. Methods of Dendrochronology-Applications in the Environmental Sciences. Dordrecht: Kluwer Academic Publishers.

Cook E R, Meko D M, Stockton C W. 1997. A new assessment of possible solar and lunar forcing of the bidecadal drought rhythm in the western United States. Journal of Climate, 10: 1343-1356.

Critchfield W B. 1980. Genetics of Lodgepole Pine. In: USDA Forest Service Research Paper WO-37. Washington, DC: United States Department of Agriculture, Forest Service.

Crowley T J. 2000. Causes of climate change over the past 1000 years. Science, 289: 270-277.

Delworth T L, Knutson T R. 2000. Simulation of early $20^{\text {th }}$ century global warming. Science, 287: 2246-2250.

Delworth T L, Rsati A, Anderson W, et al. 2012. Simulated climate and climate change in the GFDL CM2.5 high-resolution coupled climate model. Journal of Climate, 25: 2755-2781.

Dixon K W, Lanzante J R. 1999. Global mean surface air temperature and North Atlantic overturning in a suite of coupled GCM climate change experiments. Geophysical Research Letters, 26: 1885-1888.
Dixon K W, Delworth T L, Knutson T R, et al. 2003. A comparison of climate change simulations produced by two GFDL coupled climate models. Global and Planetary Change, 37: 81-102.

Findell K L, Delworth T L. 2010. Impact of common sea surface temperature anomalies on global drought and pluvial frequency. Journal of Climate, 23: 485-503.

Frankignoul C. 1999. Analysis of Climate Variability: Applications of Statistical Techniques. New York: Springer Publishers.

Fritt H C, Guiot J. 1990. Methods of calibration, verification and reconstruction. In: Cook E R, Kairiulstis L A. Methods of Dendrochronology. Dordrecht: Kluwer Academic Publishers.

George S S, Nielsen E. 2002. Hydroclimatic change in southern Manitoba since A.D. 1409 inferred from tree rings. Quaternary Research, 58: 103-111.

Grissino-Mayer H, Holmes R, Fritts H C. 1996. International Tree Rings Data Bank Program Library User’s Manual. Tucson: Laboratory of Tree-ring Research University of Arizona.

Hammersley J M. 1960. Monte Carlo methods for solving multivariable problems. Annual of the New York Academy of Sciences, 86: 844-874.

Haywood J M, Stouffer R J, Wetherald R T, et al. 1997. Transient response of a coupled model to estimated changes in greenhouse gas and sulfate concentrations. Geophysical Research Letters, 24: 1335-1338.

Hoffman P. 1998. The Man Who Loved Only Numbers: the Story of Paul Erdos and the Search for Mathematical Truth. New York: Hyperion Press.

Hoyt D V, Schatten K H. 1997. The role of the sun in climate change. Radiocarbon, 35: 215-230.

Hurrell J W. 1995. Decadal trends in the North Atlantic Oscillation: regional temperatures and precipitation. Science, 269: 676-679.

Hurrell J W. 2003. Climate Variability: North Atlantic and Arctic Oscillation. In: Holton J, Pyle J, Curry J. Encyclopedia of Atmospheric Sciences. New York: Academic Press.

IPCC. 2007. The Fourth Assessment Report of the Intergovernmental Panel on Climate Change. Cambridge: Cambridge University Press.

Koster R D, Mahanama S P P, Yamada T J, et al. 2010. Contribution of land surface initialization to subseasonal forecast skill: First results from a multi-model experiment. Geophysical Research Letters, 37, L02402, doi: 10.1029/2009GL041677.

Kutzbach J E, Bartlein P J, Foley J A, et al. 1996. Potential role of vegetation feedback in the climate sensitivity of high-latitude regions: a case study at 6000 years BP. Global Biogeochemical Cycles, 10: 727-736.

Laird K R, Fritz S C, Maasch K A, et al. 1996. Greater drought intensity and frequency before A.D. 1200 in the northern Great Plains, USA. Nature, 384: 552-554.

Liu J L, Stewart R E, Szeto K K. 2004. Moisture transport and other hydrometeorological features associated with the severe 2000/01 drought over the western and central Canadian Prairies. Journal of 
Climate, 17: 305-319.

Lotan J E, Perry A D. 1977. Fifth-year Seed: Seedling Ratios of Lodgepole Pine by Habitat Type and Seedbed Preparation Technique. In: USDA Forest Service Research Note INT-239. Ogden, Utah: United States Department of Agriculture, Forest Service, Intermountain Forest and Range Experiment Station.

Luo L, Wood E F. 2007. Monitoring and predicting the 2007 U.S. drought. Geophysical Research Letters, 34, L22702, doi: 10.1029/2007GL031673.

Manabe S, Stouffer R J. 1993. Century-scale effects of increased atmospheric $\mathrm{CO}_{2}$ on the ocean-atmosphere system. Nature, 364: 215-218.

Mann M E, Bradley R S, Hughes M K. 1999. Northern hemisphere temperatures during the past millennium: inferences, uncertainties and limitations. Geophysical Research Letters, 26: 759-762.

Mantua N J, Hare S R, Zhang Y, et al. 1997. A Pacific interdecadal climate oscillation with impacts on salmon production. Bulletin American Meteorological Society, 78: 1069-1079.

Meko D M, Therrell M D, Baisan C H, et al. 2001. Sacramento River flow reconstructed to A.D. 869 from tree rings. Journal of the American Water Resources Association, 37: 1029-1039.

Minobe S. 1997. A 50-70 year climatic oscillation over the North Pacific and North America. Geophysical Research Letters, 24: 683-686.

Minobe S. 1999. Resonance in bidecadal and pentadecadal climate oscillations over the North Pacific: role in climatic regime shifts. Geophysical Research Letters, 26: 855-858.

New M, Hulme M. 2000. Representing uncertainty in climate change scenarios: a Monte-Carlo approach. Integrated Assessment, 1: 203-213.

Nigam S, Barlow M, Berbery E H. 1999. Analysis links Pacific decadal variability to drought and stream flow in United States. EOS, Transactions American Geophysical Union, 80: 621-625.

Sauchyn D J, Beaudoin A B. 1998. Recent environmental change in the southwestern Canadian Plains. The Canadian Geographer, 42: 337-353.
Sauchyn D J, Barrow E M, Hopkinson R F, et al. 2002. Aridity on the Canadian Plains. Géographie Physique et Quaternaire, 56: 247-259.

Sauchyn D J, Stroich J, Beriault A. 2003. A paleoclimatic context for the drought of 1999-2001 in the northern Great Plains of North America. The Geographical Journal, 169: 158-167.

Schubert S, Gutzler D, Wang H L, et al. 2009. A U.S. CLIVAR project to assess and compare the responses of global climate models to drought-related SST forcing patterns: overview and results. Journal of Climate, 22: 5251-5272.

Sheppard W D, Noble D L. 1976. Germination, Survival, and Growth of Lodgepole Pine under Simulated Precipitation Regimes: a Greenhouse Study. In: USDA Forest Service Research Note RM-328. Fort Collins: United States Department of Agriculture, Forest Service, Rocky Mountain Forest and Range Experiment Station.

Stuiver M, Reimer P J, Bard E, et al. 1998. INTCAL 98 radiocarbon age calibration, 24,000-0 cal BP., 40: 1041-1083.

Touchan R, Meko D M, Hughes M. 1999. A 396-year reconstruction of precipitation in southern Jordan. Journal of the American Water Resources Association, 35: 49-59.

Vincent L A, Gullett D W. 1999. Canadian historical and homogenous temperature datasets for climate change analysis. Journal of Climatology, 19: 1375-1388.

Wiken E B. 1986. Terrestrial Ecozones of Canada. In: Ecological Land Classification Series No. 19. Ottawa: Environment Canada, Lands Directorate.

Wolfe S A, Huntley D J, David P P, et al. 2001. Late $18^{\text {th }}$ century drought-induced sand dune activity, Great Sand Hills, Saskatchewan. Canadian Journal of Earth Sciences, 38: 105-117.

Yu G, Shen H D. 2010. Lake water changes in response to climate change in northern China: simulations and uncertainty analysis. Quaternary International, 212: 44-56.

Zhang X, Vincent L A, Hogg W D, et al. 2000. Temperature and precipitation trends in Canada during the $20^{\text {th }}$ century. Atmosphere -Ocean, 38: 395-429. 